\title{
Paradoxical air embolism during percutaneous nephrolithotomy due to patent foramen ovale: Case report
}

\author{
Daljeet Chahal,; Vladimir Ruzhynsky, MD; ${ }^{\dagger}$ lain McAuley, MD; $;$ Desmond Sweeney, MD; $;$ Paul Sobkin, MD;* \\ Michael Kinahan, $M D_{;}^{*}$ Rich Gardiner, MD; John Kinahan, $M D^{ \pm}$
}

*University of British Columbia, Vancouver, BC; ${ }^{\circledR}$ McMaster University, Hamilton, ON; *Victoria, BC; ”Kelowna, BC

Cite as: Can Urol Assoc J 2015;(9-10):E658-60. http://dx.doi.org/10.5489/cuaj.2835 Published online September 9, 2015.

\section{Abstract}

Paradoxical air embolism is a very rare complication associated with percutaneous nephrolithotomy (PCNL). Incidence may be higher if patients also suffer from a septal heart defect. We report the case of a 76-year old male who presented for PCNL treatment of a right kidney lower calyceal calculus. During the procedure, the patient developed signs and symptoms consistent with that of air embolism. Intraoperative echocardiography confirmed the diagnosis. Subsequent intraoperative and postoperative medical management was carried out and the patient was discharged after recovery three days later. This case highlights the importance of a rare but potentially fatal complication of PCNL.

\section{Introduction}

Air embolus is a potentially fatal complication of surgical or interventional procedures with an array of systemic complications. Its incidence during percutaneous nephrolithotomy (PCNL) is rare. Symptomatic paradoxical air embolism may be more likely in patients with septal heart defects. We report the case of a patient who developed systemic manifestations of a paradoxical air embolus likely due to a previously undiagnosed right to left shunt. This case highlights consequences of air embolus, as well as appropriate management.

\section{Case report}

A 76-year-old man underwent elective percutaneous nephrolithotomy (PCNL) to manage a $1.9-\mathrm{cm}$ right lower pole calculus (Fig. 1). With the patient in a prone position, access to the right renal collecting system was obtained through a lower pole calyx set using fluoroscopic guidance.
Minimal distention of the renal pelvis was observed and the collecting system was not adequately visualized despite repeated air insufflation. Retrograde pyelogram confirmed that the dilator was appropriately placed in the renal pelvis. Additional air was insufflated, bringing the total to $240 \mathrm{~mL}$.

Acute drops in blood pressure and end tidal $\mathrm{CO}_{2}$ were observed. The procedure was terminated and the patient was repositioned in supine position for resuscitation. A transesophageal echocardiogram (TEE) was performed during resuscitation (Fig. 2). Initially, the left atrium was collapsed with significant air present in both sides of the heart. Air was visualized leaving the left ventricle through the aortic valve. The intra-atrial septum was bowing to the left, appearing aneurysmal in nature. At this point, the patient sustained a self-limited ventricular tachycardia and electrocardiogram demonstrated right bundle branch block with ST elevation in inferior leads which resolved with ongoing ionotropic support. Echocardiography also demonstrated improvement of ventricular function. Colour flow Doppler analysis of the septum did not demonstrate a distinct patent foramen ovale (PFO). However, based on the bowing of the septum and significant left sided air, a right to left shunt was suspected.

The patient was subsequently managed in the intensive care unit. Bloodwork demonstrated hypoxemia, carboxyhemoglobinemia, electrolyte abnormalities, and significant elevation of Troponin $\mathrm{T}$. The patient remained intubated and perfusion pressure was maintained with inotropes. Pulmonary edema noted on radiograph was managed with diuretics. Subsequent workup demonstrated stabilization of serum electrolytes and dissipation of pulmonary edema. Ultimately, the patient was weaned off inotropes, extubated and discharged 3 days after the event.

\section{Discussion}

Previous reports of venous air embolism associated with percutaneous renal surgery have occurred during air pyelography,,$^{1-7}$ percutaneous access alone ${ }^{8}$ or retrograde injection 


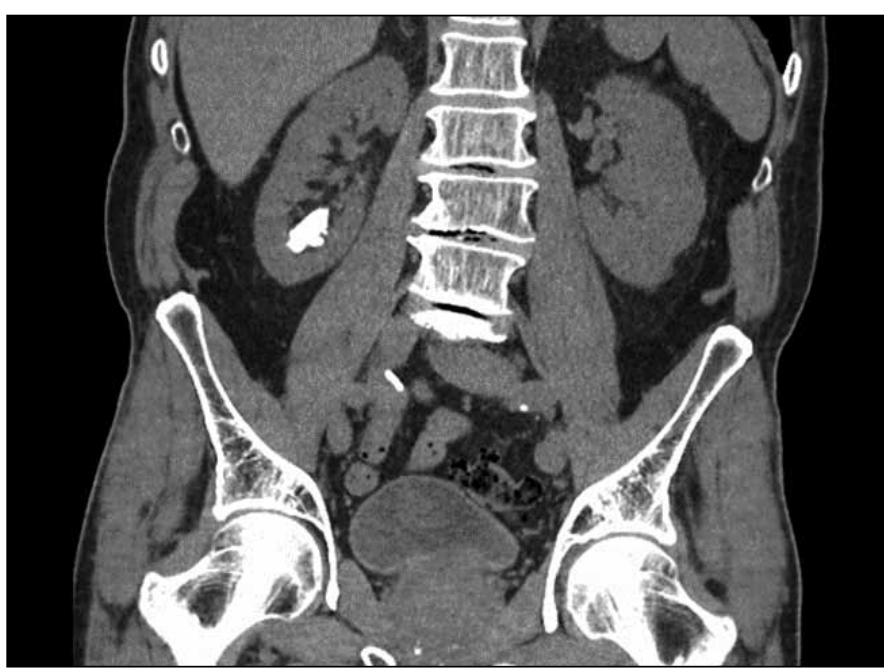

Fig. 1. Coronal CT scan demonstrating a $1.9-\mathrm{cm}$ right lower pole calculus.

of air prior to percutaneous access. ${ }^{9,10}$ The risk of patient mortality has been highlighted in these cases. ${ }^{8}$

During PCNL, air may enter renal veins from the pelvicalyceal system. ${ }^{11}$ Subsequent entry into the right heart will obstruct the pulmonary outflow tract and/or pulmonary microcirculation. If capacity of the lung is exceeded, air emboli may pass through pulmonary capillaries and enter systemic circulation. Additionally, air may reach circulation by direct entry or paradoxical embolization through septal defects such as a PFO. ${ }^{9,12}$ Interestingly, septal defects, such as PFOs, persist in up to one-fourth of the general population. ${ }^{13,14}$ Factors influencing the possibility of embolism include volume of air insufflated, the rate of insufflation, and patient positioning. ${ }^{9}$

In our case, air entered circulation through a right to left shunt, inducing an intra-operative myocardial infarction. Unfortunately, $240 \mathrm{~mL}$ was insufflated during this case due to inadequate visualization. The pelvi-calyceal system has a $30 \mathrm{~mL}$ capacity and it is likely the system's capacity was exceeded.

Symptoms of air embolism include tachycardia, hypotension, mental status changes, and neurological defects. Initial intraoperative diagnosis of air embolus is based on hypotension and decreased end tidal $\mathrm{CO}_{2} \cdot{ }^{15}$ The diagnosis may be confirmed with intra-operative echocardiography or postoperative computed tomography. Droghetti and

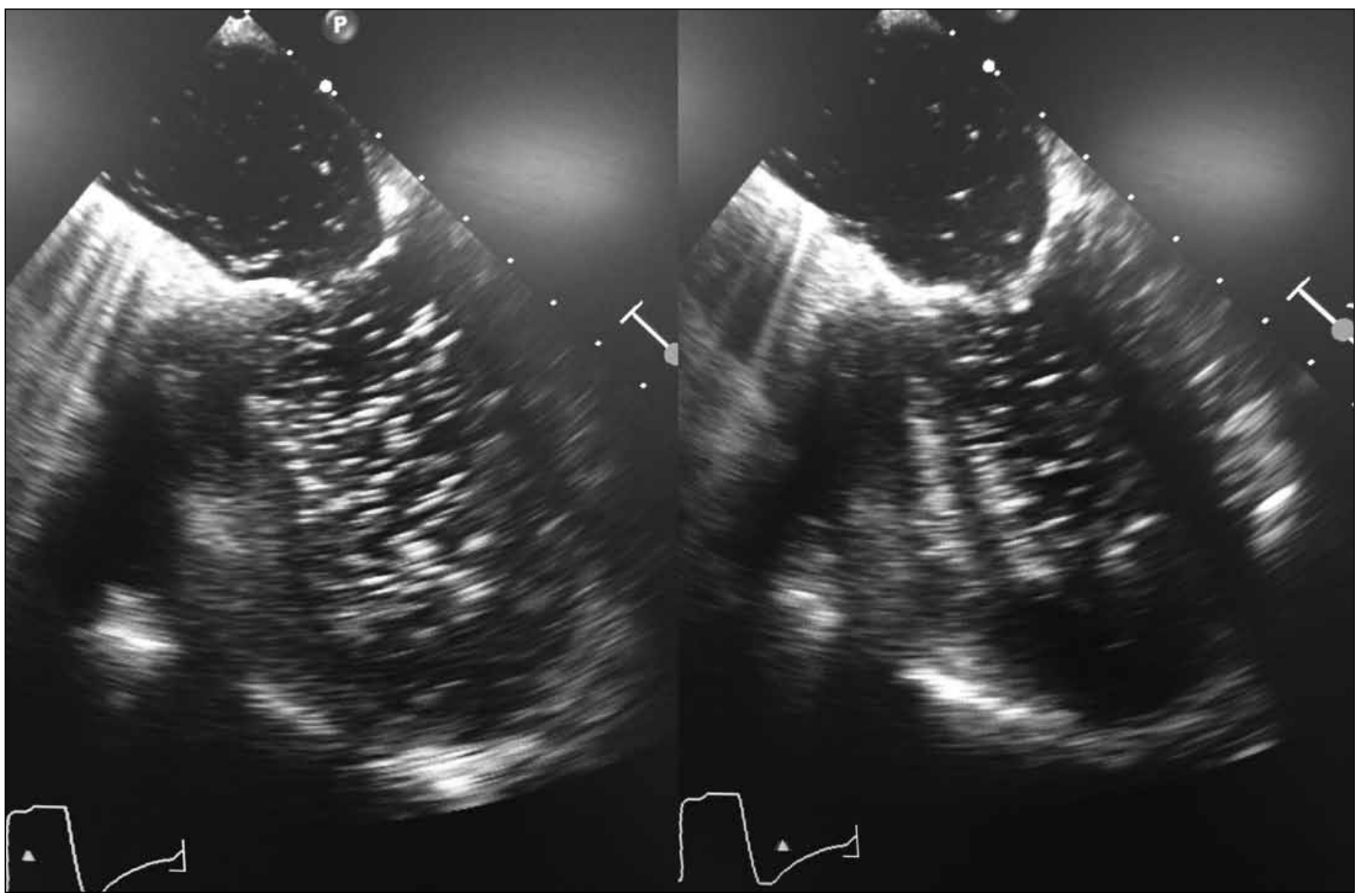

Fig. 2. Simulated intra-operative trans-esophageal echocardiogram demonstrating air within heart chambers. Note that this echocardiogram is simulated and not taken from the presented case as that data was inaccessible after the operation. 
colleagues diagnosed an air emboli using single-photon emission tomography, ${ }^{1}$ but they were unable to confirm the presence of a septal defect. In our case, intra-operative TEE demonstrated air in both sides of the heart, suggesting paradoxical embolism. One prior case of paradoxical vascular air embolism during PCNL has been reported. ${ }^{9}$ In that case, the patient suffered a seizure 8 hours post-procedure, and TEE provocation testing demonstrated a PFO although emboli was never confirmed.

Management of venous gas embolus begins with procedure termination, continuous oxygenation, and Trendelenburg and left lateral decubitus patient positioning. Hemodynamic stability is maintained with inotropic support. ${ }^{15,16}$ Aspiration of air from the right atrium is appropriate if a catheter is already in place. ${ }^{15}$ If necessary, chest compressions and full cardiopulmonary resuscitation should be initiated. Patients with stable cardiopulmonary status with signs of cerebral embolism may benefit from hyperbaric oxygen therapy. ${ }^{1}$ In our case, the patient was successfully managed with resuscitative efforts and transferred to the intensive care unit. Hyperbaric therapy was not needed.

Complications of air embolus vary. The patient in our case displayed decreased level of consciousness, but no focal deficits or seizures. ${ }^{17} \mathrm{He}$ did suffer an intra-operative myocardial infarction with elevated troponins. No prior cases of PCNL air emboli have documented infarction, but this is known to happen in high-risk procedures, such as cardiac surgery. ${ }^{18} \mathrm{~A}$ retrospective review by Lee and colleagues documented PCNL complications, including one myocardial infarction. ${ }^{19}$ That patient did not suffer air emboli and had other risk factors. Emboli may induce pulmonary hypertension leading to decreased cardiac output and subsequent myocardial ischemia. They may also directly occlude coronary arteries. ${ }^{20}$ In our report, a right to left shunt provided the emboli with a direct path to the coronary arteries. This complication highlights that patients with septal defects may have a higher risk of complication from procedures, such as PCNL.

\section{Conclusion}

Our patient experienced complications of air embolus while undergoing PCNL for a large calculus. Systemic complications included myocardial infarction, likely due to a right to left cardiac shunt. This case demonstrates that physicians performing PCNL should be aware of this potentially fatal complication as well as its management.
This paper has been peer-reviewed.

\section{References}

1. Droghetti L, Giganti M, Memmo A, et al. Air embolism: Diagnosis with single photon emission tomography and successful hyperbaric oxygen therapy. Br J Anaesth 2002;89:775-8. http://dx.doi.org/10.1093/ bja/89.5.775

2. Cadeddu JA, Arrindell D, Moore RG. Near fatal air embolism during percutaneous nephrostomy placement. J Urol 1997;158:1519. http://dx.doi.org/10.1016/S0022-5347(01)64258-7

3. Miller RA, Kellett MJ, Wickham JE. Air embolism, a new complication of percutaneous nephrolithotomy. What are the implications? J Urol (Paris) 1984;90:337-9.

4. Kachalia AG, Savant CS, Patil S, et al. Cerebral and spinal air embolism following percutaneous nephrolithotomy. J Assoc Physicians India 2011;59:254-6.

5. Basumatary L, Bhowmick S, Sarma K, et al. Cerebrospinal air embolism following percutaneous nephrolithotomy: Gravitational gradient effect. Neurol India 2014;62:221. http://dx.doi.org/10.4103/00283886.132444

6. Parikh GP, Sonde SR, Kadam P. Venous air embolism: A complication during percutaneous nephrolithotomy. Indian J Urol 2014;30:348-9. http://dx.doi.org/10.4103/0970-1591.128510

7. Hegland DL, Canales BK, Katz RI. Quadriparesis from air emboli during percutaneous nephrolithotomy. J Clin Anesth 2014;26:318-20. http://dx.doi.org/10.1016/i.jdinane.2014.01.007

8. Turillazzi E, Pomara C, Bisceglia R, et al. Vascular air embolism complicating percutaneous nephrolithotomy: Medical malpractice or fatal unforeseeable complication? Urology 2009;73:681.e1-681.e4. http:// dx.doi.org/10.1016/i.urology.2008.03.028

9. Song S-H, Hong B, Park HK, et al. Paradoxical air embolism during percutaneous nephrolithotomy: A case report. J Korean Med Sci 2007;22:1071-3. http://dx.doi.org/10.3346/jkms.2007.22.6.1071

10. Varkarakis J, Su L-M, Hsu THS. Air embolism from pneumopyelography. J Urol 2003;169:267. http:// dx.doi.org/10.1016/S0022-5347(05)64084-0

11. Lopez FA, Dalinka M, Doboy JG. Pyelovenous backflow: Facts, fallacies and significance. Urology 1973;2:612-4. http://dx.doi.org/10.1016/0090-4295(73)90319-1

12. ArnottC, Kelly K, Wolfers $D$, et al. Paradoxical cardiac and cerebral arterial gas embolus during percutaneous lead extraction in a patient with a patent foramen ovale. Heart Lung Circ 2015;1:e14-17. http://dx.doi. org/10.1016/i.hc.2014.09.002

13. Hagen PT, Scholz DG, Edwards WD. Incidence and size of patent foramen ovale during the first 10 decades of life: An autopsy study of 965 normal hearts. Mayo Clin Proc 1984;59:17-20. http://dx.doi. org/10.1016/S0025-6196(12)60336-X

14. Handke $M$, Harloff $A$, Olschewski $M$, et al. Patent foramen ovale and cryptogenic stroke in older patients. NEJM 2007;357;2262-268. http://dx.doi.org/10.1056/NEJMoa071422

15. Mirski MA, Lele AV, Fitzsimmons L, et al. Diagnosis and treatment of vascular air embolism. Anesthesiology 2007;106:164-77. http://dx.doi.org/10.1097/00000542-200701000-00026

16. Archer DP, Pash MP, MacRae ME. Successful management of venous air embolism with inotropic support. Can J Anaesth 2001;48:204-8. http://dx.doi.org/10.1007/BF03019737

17. Öztürk H. Neurologic complications of percutaneus nephrolithotomy. Int Neurourol J 2014;18:45-7. http://dx.doi.org/10.5213/inj.2014.18.1.45

18. Lee HY, Yoo SM. A case of paradoxical air embolism in the coronary artery through a patent foramen ovale demonstrated by coronary CT angiography. Clin Imaging 2013;37:167-9. http://dx.doi.org/10.1016/i. clinimag.2012.04.001

19. Lee WJ, Smith AD, Cubelli V, et al. Complications of percutaneous nephrolithotomy. AJR Am J Roentgenol 1987;148:177-80. http://dx.doi.org/10.2214/air.148.1.177

20. Shroff GR, Sarraf $M$, Sprenkle MD, et al. Air embolism involving the coronary and pulmonary circulation: An unusual cause of sudden cardiac death. Circulation 201 1;124:2949-50. hittp://dx.doi.org/10.1161/ CIRCULATIONAHA.111.039164

Correspondence: DalieetChahal, University of British Columbia, Vancouver, BC; daljeet@@ulumni.ubc.ca 